\title{
21the Wheelchair Project Case Study: Leveraging Collaborative Efforts and Partnerships to Provide Assitive Devices for People Affected by Disability in Thailand and Southeast Asia
}

\section{Tell, Joseph David}

General Manager, RICD Wheelchair Project, Rajanagarindra Institute of Child Development, Thailand

Corresponding Author: Joseph Tell, General Manager, RICD Wheelchair Project, Rajanagarindra Institute of Child Development, Thailand.

Received date: November 23, 2021; Accepted date: December 18, 2021; Published date: January 06, 2022

Citation: Joseph Tell, (2021) 21 the Wheelchair Project Case Study: Leveraging Collaborative efforts and Partnerships to provide Assitive Devices for People Affected by Disability in Thailand and Southeast Asia. J. Archives of Medical Case Reports and Case Study, 5(2); DOI:10.31579/26929392/096

Copyright: (C) 2022 Joseph Tell. This is an open access article distributed under the Creative Commons Attribution License, which permits unrestricted use, distribution, and reproduction in any medium, provided the original work is properly cited.

\begin{abstract}
Many people affected by disability require assistive devices, particularly mobility aids, in order to live independently and fully integrate into their communities. Throughout the world, numerous methods have been implemented in facilitating the provision of these devices to people affected by disabilities. This case study intends use the Rajanagarindra Institute of Child Development Wheelchair Project, located in Chiang Mai, Thailand, to evaluate the viability and efficacy of mobility-provision programs which adapt wheelchairs and other assistive devices not originally intended for the end user. Programs which must "retro-adapt" equipment, like the Wheelchair Project, rely heavily on medical and mechanical expertise to identify the recipients' needs and safely modify the device accordingly. By examining the distribution statistics from the Wheelchair Project over its 20 years of operation and the needs of the disability community reported by the National Statistics Office of Thailand alongside a cost-benefit analysis of the declared value provided versus operational cost, this case-study systematically details the scope and financial viability of this approach. While not without constraints, this model succeeds in effectively capitalizing on available resources (both in regard to physical equipment as well as professional expertise) to meet the needs of those affected by disabilities in Thailand and Southeast Asia. Although still limited in size and reach, the Wheelchair Project demonstrably shows its viability and the potential this approach presents given the right circumstances.
\end{abstract}

Key words: assitive technology; disability, mobility; handicapped; provision; wheelchair; ricd wheelchair project; second-hand equipment; world health organization service training package

\section{INTRODUCTION}

The RICD Wheelchair Project was established in 1999 under the Rajanagarindra Institute of Child Development with the mission to provide equipment to people affected by disabilities who did not have access or means to acquire wheelchairs or other aids that met their needs. Those involved with the Wheelchair Project's initial undertaking could not have predicted the demand for this type of program, nor fully appreciate the complexity and effort providing a properly fit wheelchair entail.

Data shows that postural support and the proper use of mobility-aid-type assistive devices offers numerous benefits to the user and the community at large through the increased activity level that comes with independence, which has been clearly linked to better overall health, (Ploeg, Beek, Van Der Woude, \& Mechelen, 2004; Barks, 2004) coordination, (Rochat, 1992) improved socialization and overall attitude. (Bray, Noyes, Edwards, \&
Harris, 2014) Use of mobility technologies have proved beneficial to respiratory and circulatory complications (Harris, Pinnington, \& Ward, 2005) as well as directly contributing to mitigating a patient's decline in health (Harris et al., 2005 ; Ploeg et al., 2004 ; Summer, Oconnell, Macalpine, 2017). Additionally, a patient's emotional and mental health is positively correlated with improved mobility and independence (RousseauHarrison, \& Rochette, 2012), particularly in instances of individuals who previously were without (Shore, 2017).

Other benefits associated with access to assistive devices include higher community involvement (Glumac, Pinnington, \& Ward, 2005; Summer et al., 2017) and employment rates (Shore, 2017), which directly affect an individual's ability to contribute to the economy and ease the financial strain on their families and governments (Bickenbach, 2011). The WHO estimates that governments lose approximately $6.7 \%$ of their GDP due to the $\sim 80 \%$ unemployment rate of individuals affected by disabilities and their lack 
taxable income or being able to contribute into the economy (Bickenbach, 2011). In Thailand, only $23.9 \%$ of the populations with disabilities were employed (Toro, Eke, \& Pearlman, 2015). These vocational limitations are directly linked to under-developed educational resources. $65.3 \%$ of individuals in Thailand with a disability between the ages of 5-24 have received no education whatsoever, and less than $15 \%$ achieving anything beyond primary schooling (The 2017 Disability Survey). Currently nearly $15 \%$ of the population who have disabilities are currently in need and without access to the assistive device they require (The 2017 Disability Survey).

However, many mobility technologies, particularly wheelchairs, require medical and technical expertise when being adapted to meet the patients' needs (Toro et al., 2015). These modifications, which vary in complexity between different individuals, must be carried out under trained mechanical and medical supervision, as an improper fitting could exacerbate a patient's condition or even introduce additional health complications or abandonment of the device due to pain, fatigue, discomfort, environment incompatibility, or damage (Shore, 2017). This necessity for individualized care on a patientby-patient basis indicates that professional capacity must be developed in tandem with equipment supply.

The RICD Wheelchair Project team works to ensure each patient who receives service is given the best possible care. This is achieved through the coordinated efforts of trained technicians and medical personnel throughout the planning, preparation, and fitting process. This beings with the local hospitals and organizations who help collect patient information and needs, which is compiled with other patient applications and submitted to the Wheelchair Project staff for review. These applications are used to select wheelchairs or mobility aids specific to the patients' physical, environmental, or lifestyle needs. This selection is reviewed by on-staff therapists and technical personnel before being sent out for delivery. On a pre-determined date, the Wheelchair Project arranges for its team members to hold a local "Distribution Event" where patients will be given another inperson evaluation and receive a device appropriate to their needs and fit to their specifications. This process can potentially take hours, requiring complex adaptations to be made to their wheelchair, so it is essential to have multiple teams working independently to cut down on wait time. After the individual receives their wheelchair, they are given safety training on its proper use and any special features that it may have. While the number of patients able to be seen in a single day varies depending on complexity of fittings or the number of available teams to carry out these fittings, the average case load for a single workday is approximately 40 patients. This number has increased significantly from previous years - approximately 20 - due in large part to increased efficiency of the fitting process and patientspecific preparations now being made to the equipment before being sent out.

\section{Objectives}

By synthesizing 20 years of statistical data, this case study will evaluate the scale of demand for the services offered by the Wheelchair Project by plotting the overall trends of the project's output, activities, and reach. Additionally, a cost-benefit analysis of the value of the equipment and services offered by the Wheelchair Project compared with the upkeep cost needed to maintain its ongoing efforts. Together, this data will serve to demonstrate the overall viability of the Wheelchair Project and others of similar design.

\section{Methods}

Given that the primary function of the Wheelchair Project is to provide mobility aids to individuals affected by disability, the question of "impact" or "value" becomes a very difficult thing to quantify. To the recipient, a wheelchair means significantly more than the device itself. It represents independence, access to community, education, or job opportunities. Monetary valuation on a non-commodity subjects is - by itself - difficult to calculate, but this difficulty is further compounded when these subjects are directly related to human beings and their quality of life.

In efforts to objectively measure and evaluate the Wheelchair Project, two primary categories were selected - (1) Scope and (2) Financial Viability - as measured through the following sub-categories: (1)(a) Equipment Distributed ; (1)(b) Services Offered ; (1)(c) Outreach Proximity ; (2)( a) Market Value of Equipment Given ; (2)(b) Donations in Kind ; (2)(c) Total Operational Cost ; and (2)(d) Sustainability. These two primary categories were selected due to their merits in evaluating the Wheelchair Project as a model and their predominantly objective data.

\section{Results}

\section{(1)(a) Equipment Distributed}

Equipment Distributed - or "work output" - is an ideal statistic to begin with, describing how many pieces of equipment (broken down into "Wheelchairs" and "Various" sub-categories) have been given away each year. These statistics show that the latest year - 2019 - compared to the year work production began - 2000 - has seen an increase of total mobility aids provided by a factor of more than 10x, with average growth, year by year, of approximately $20 \%$ (Table 1 ). Of the information available, approximately $91 \%$ of equipment provided went to a first-time patient of the Wheelchair Project, many of whom were receiving their first wheelchair for private use. It is worth noting that estimated value of equipment given was derived from Average Market Value in Thailand if available, and value declared by donor if unavailable.

\begin{tabular}{|c|c|c|c|c|}
\hline $\begin{array}{l}\text { February } \\
\text { Expenses }\end{array}$ & & & & \\
\hline Date & Expense & Amount & Category & \\
\hline $1 / 2 / 2021$ & Cushion Covers & 8,457 & Supplies & \\
\hline $2 / 2 / 2021$ & Paper & 340 & Evangelism & \\
\hline $3 / 2 / 2021$ & Microphon & 5690 & $\begin{array}{c}\text { Media } \\
\text { Development }\end{array}$ & \\
\hline $5 / 2 / 2021$ & Drill Bits & 909 & Supplies & \\
\hline $10 / 2 / 2021$ & $\begin{array}{c}\text { Catterpillar } \\
\text { Clips }\end{array}$ & 220 & Supplies & \\
\hline $13 / 2 / 21$ & $\begin{array}{c}\text { Tools and } \\
\text { Supplies }\end{array}$ & 1475 & Supplies & \\
\hline
\end{tabular}




\begin{tabular}{|c|c|c|c|c|}
\hline $14 / 2 / 21$ & Paper & 240 & Evangelism & \\
\hline $16 / 2 / 21$ & Cushion Covers & 1800 & Supplies & \\
\hline $19 / 2 / 21$ & Hydrolic Lift & 865 & Supplies & \\
\hline $22 / 2 / 21$ & Inner Tubes & 240 & Supplies & \\
\hline $22 / 2 / 21$ & WiFi Card & 399 & Supplies & \\
\hline $24 / 2 / 21$ & CDs & 590 & Evangelism & \\
\hline $24 / 2 / 21$ & Outer Tubes & 579 & Supplies & \\
\hline $25 / 2 / 21$ & Copy Keys and & 7,285 & Infastructure & \\
\hline $25 / 2 / 21$ & Tools and Lathe & 1625 & Supplies & \\
\hline $27 / 2 / 21$ & Dremmel Bits & 126 & Supplies & \\
\hline $28 / 2 / 21$ & Tools & 1218 & Supplies & \\
\hline & & & & \\
\hline Totals & & & & \\
\hline Suplies & 17,913 & & & \\
\hline Evangelism & 1170 & & & \\
\hline
\end{tabular}

\begin{tabular}{|l|l|l|l|l|}
\hline February Expenses & & & & \\
\hline Date & Expense & Amount & Category & \\
\hline $1 / 2 / 2021$ & Cushion Covers & 8,457 & Supplies & \\
\hline $2 / 2 / 2021$ & Paper & 340 & Evangelism & \\
\hline $3 / 2 / 2021$ & Microphon & 5690 & Media Development & \\
\hline $5 / 2 / 2021$ & Drill Bits & 909 & Supplies & \\
\hline $10 / 2 / 2021$ & Catterpillar Clips & 220 & Supplies & \\
\hline $13 / 2 / 21$ & Tools and Supplies & 1475 & Supplies & \\
\hline $14 / 2 / 21$ & Paper & 240 & Evangelism & \\
\hline $16 / 2 / 21$ & Cushion Covers & 1800 & Supplies & \\
\hline $19 / 2 / 21$ & Hydrolic Lift & 865 & Supplies & \\
\hline $22 / 2 / 21$ & Inner Tubes & 240 & Supplies & \\
\hline $22 / 2 / 21$ & WiFi Card & 399 & Supplies & \\
\hline $24 / 2 / 21$ & CDs & 590 & Evangelism & \\
\hline $24 / 2 / 21$ & Outer Tubes & 579 & Supplies & \\
\hline $25 / 2 / 21$ & Copy Keys and Lathe & 7,285 & Infastructure & \\
\hline $25 / 2 / 21$ & Tools and Lathe & 1625 & Supplies & \\
\hline $27 / 2 / 21$ & Dremmel Bits & 126 & Supplies & \\
\hline $28 / 2 / 21$ & Tools & 1218 & Supplies & \\
\hline & & & & \\
\hline Totals & 17,913 & & & \\
\hline Suplies & & & & \\
\hline
\end{tabular}

Table 1: Distribution Stats $2000-2019$

(1)(b) Services Offered
Services Offered looks at how many different methods the Wheelchair Project utilizes in its pursuit to supply equipment. The two primary fields of 
service are individual care (adjustment/distribution/repair of equipment as described previously) and long-term efforts involving systemic change. This primarily takes the form of medical/technical training programs and the innovations and reference materials available as support elements to the trainees. Of particular note within these expanded services is the training program, which follows the World Health Organization's "Wheelchair Service Training Package," under which trainees who complete this course have the opportunity to receive accreditation given by the International Society of Wheelchair Professionals, contingent on a passing grade of the testing and evaluation modules required. The expectation is that this program will yield a network of trained medical and technical partners throughout the region that offer year-round services.

\section{(1)(c) Outreach Proximity}

The third criteria to measure the Wheelchair Project's scope, particularly its progression over the years, is Outreach Proximity. This metric is particularly useful in highlighting widespread interest in the work efforts of the Wheelchair Project. The Wheelchair Project, based in Chiang Mai, Thailand, initially only offered its services city-wide before quickly being invited to nearby provinces the very next year, and later expanding to every other regions and countries. To date, the Wheelchair Project has held more than 250 distribution events in nearly every province of Thailand and all bordering countries (Malaysia, Myanmar, Laos, and Cambodia).

\section{(2)(a) Market Value of Equipment Given}

Evaluating the Market Value of Equipment given by the Wheelchair Project necessitates finding the average cost of comparable items available on the 2nd-hand market. This was done by looking through compiling used listings available locally online, eliminating outlier listings priced either overly high or low, and taking a median sample for the "Market Value" of that equipment type. This was carried out for every equipment type with a total inventory count for that type equal to $1 \%$ or greater of the total inventory volume received by the Wheelchair Project. These "market values" are updated in intervals of approximately 1 year to accurately reflect current real-world valuation. It is worth noting that this practice has only been in place for the previous 5 years, with prior years reporting less consistent values. Where Market Value was not available, estimated value was derived from the estimates of the donating organization and their own evaluation, which has been consistently and markedly lower than Thailand Market Values. To date, the Wheelchair Project has provided 297,154,310 THB ( 9.6 million USD) worth of equipment to people affected by disabilities. (Yearly value of donated equipment year-by-year available in Table 1)

\section{(2)(b) Donations in Kind}

Donations in Kind are a significant factor in the Wheelchair Project's proliferation. Even without the inclusion of the value of equipment donated to the Wheelchair Project, as listed above, the Donations in Kind are valued in the millions of Thai Baht. (Table 2) There are numerous organizations and individuals which contribute services or goods in the support of the Wheelchair Project efforts. A majority of the Wheelchair Project workforce are non-salaried volunteers or voluntarily working for a lower income than other work opportunities available. Additionally, the shipment, import, and transportation of all equipment is provided for free by a major supporting company. Even the accommodation, transportation, and logistics expenses that every distribution or training event require are covered by the local hospitals, municipalities, partners, or other entities. While nearly impossible to adequately calculate, the expense these stakeholders save the Wheelchair Project are estimated at a minimum of 3 million THB and often much higher - 2019, for example, Donations in Kind were valued at approximately 7.7 million THB.

\section{(2)(c) Total Operational Cost}

Donations in Kind is directly linked to the Total Operational Cost of the Wheelchair Project, which will compare the Potential Cost and Actual Cost needed to sustain the ongoing activities of the Wheelchair Project, specifically for the year 2019. Please note that the "Potential Cost" figures are calculated estimates drawn from real-world quotations of identical or similar goods and services offered by the contributing company itself or comparable company if data is unavailable.

\begin{tabular}{|l|l|l|l|}
\hline Item & Description/Remark & Potential Cost & Actual Cost \\
\hline Tools and Supplies & Derived via tools/supplies acquired & 500,000 & 419,146 \\
\hline Staff/Workers & $\begin{array}{l}\text { Estimated via typical salary of hospital worker in } \\
\text { Thailand applied to all workers, including volunteer } \\
\text { staff }\end{array}$ & $4,704,000$ & 189,480 \\
\hline $\begin{array}{l}\text { Equipment Transportation } \\
\text { (Domestic) }\end{array}$ & $\begin{array}{l}\text { Estimated from domestic shipping costs for 23 } \\
\text { Events }\end{array}$ & $1,115,000$ & 10,000 \\
\hline $\begin{array}{l}\text { Equipment Transportation } \\
\text { International) }\end{array}$ & $\begin{array}{l}\text { Estimated from international shipping costs for 11 } \\
\text { Container Shipments }\end{array}$ & $1,100,000$ & 0 \\
\hline Distribution Event & Estimated via food, hotel, transportation of staff & 920,000 & 38,680 \\
\hline Project Upkeep & Estimated using average upkeep cost & 339,758 & 273,758 \\
\hline & & $8,678,758$ & 931,064 \\
\hline
\end{tabular}

Table 2: Expense Overview 2019 (Thai Baht)

Of note is Actual Cost for the Wheelchair Project is a mere $1.5 \%$ of the Market Value given away in 2019; even if there were no subsidizations through Donations in Kind the total Operational Cost would still only rise to $13.6 \%$ of the Market Value of its 2nd-hand equipment provided to people affected by disabilities. It is worth note that "Potential Cost" calculations are rough estimates and subject to numerous mitigating factors that affect realworld cost or value. The emphasis here is not the value of Donations in Kind given to the Wheelchair Project - the emphasis is on the value of collaborative efforts in general.

\section{(2)(d) Sustainability}

Finally, evaluation of the Sustainability of the Wheelchair Project will appraise the apparent reliability and longevity of current support systems as well as the scalability of its model. As noted throughout this case study, the proliferation of the Wheelchair Project is driven primarily by its numerous 
supporting or contributing partners. Having this wide partnership base has enabled the Wheelchair Project access to multiple sources for inventory supply from multiple originating countries, financial donations, transportation partners, volunteer advocacy platforms, and patient liaison entities. This diversification of partners ensures that ongoing activities are not solely dependent on any single contributor. And although output could potentially drop significantly should certain partners cease cooperation, the Wheelchair Project would almost certainly not suffer cessation altogether.

Additionally, equipment supply potential and patient demand within Thailand are under-saturated at the time of writing, with hundreds of thousands of individuals in Thailand (Thailand National Statistics Office, 2020) in need of equipment and multiple equipment donor organizations prepared to supply additional shipments of mobility aids to the Wheelchair Project. This disparity of need/availability and the output currently being offered by the Wheelchair Project is the foundation for the training and propagation efforts recently put into effect.

\section{Limitations}

While the findings detailed in this case study indicate strong potential for the re-distribution model employed by the Wheelchair Project, no sweeping determinations can be made until further data is collected from additional assistive device provisioners in a variety of environments. To put this more plainly, this case study documents a single project's relief efforts, and it is impossible to definitively identify which factors were instrumental to the Wheelchair Project's success. Attributes of the Wheelchair Project which are clearly advantageous include its status as a Royal Project with allowances that facilitate import and distribution of equipment as well as the close cooperation from the Thai Medical Council, Ministry of Public Health, and the network of government hospitals throughout Thailand. Furthermore, the international network of partners who collect, refurbish, and facilitate the transport and the delivery of equipment from abroad remain an integral part of the Wheelchair Project's operation. These aspects of the Wheelchair Project are the result of years of hard work and are not easily replicated.

It is important to note that as manufacturing techniques and global logistic systems develop, there are increasing numbers of alternative sources for equipment available at extremely low cost, with some providing equipment at-cost or even free of charge to approved provisioners. These manufacturers achieve this through the economies of scale by bulk-producing a select few equipment types, using lower-cost materials, optimizing the equipment design for production or transportation, vertical integration, subsidizing end user cost through alternative funding, or a combination of these techniques. Many of these offerings typically have low adaptability, limiting the number of patients able to use them. The Wheelchair Project currently does not receive or distribute any equipment types of this nature and cannot speak to the merits or drawbacks these pieces introduce for provisioning programs.

Finally, this case study fails to include any analysis of recipients' long-term condition once having received an assistive device from the Wheelchair Project. It is paramount that assistive devices such as wheelchairs and other mobility aids be appropriately selected and adjusted in accordance with the physical, environmental, and ADL (Activities of Daily Living) needs of each recipient. These fittings must be updated and the equipment re-adapted as the patient grows, develops, or as their condition requires; this is particularly important for pediatric patients whose bodies are rapidly changing and developing. (Khasnabis \& Mines, 2013) Due to the Wheelchair Project's prioritization of first-time patients - that is, patients currently without an assistive device - as well as the challenges posed by the proximity most distributions occur from Chiang Mai, data on post-fitting patients' condition is extremely limited.

\section{Discussion}

Global population trends continue to see positive growth rates year-over-year with projections predicting continued growth across almost all population sectors, including the overall number of people affected by disability, for the foreseeable future. (ourworldindata.org) The WHO estimates that there are currently 1 billion people - approximately $15 \%$ of the world's population currently living with "moderate to severe" disabilities; in 1970, people affected by disabilities were estimated to have made up approximately $10 \%$ of the world's population. (Bickenbach, 2011) This is primarily due to advances in medical services and better living conditions, particularly in more wealthy nations. (Bickenbach, 2011) Assuming these predictions are accurate, as the population of individuals affected by disability increases there will be a proportionate increase in demand for assistive devices demand which is already inadequately met. Meeting this need will require robust programs with widespread adoption which can keep pace with the population growth.

Despite clearly demonstrating viability, the Wheelchair Project's year-overyear growth remains outpaced compared to localized population growth of persons with disabilities recorded by Thailand's National Statistics Office. In 2012 it was reported that approximately 297,003 individuals in Thailand were in need of assistive devices out of the total population affected by disabilities $(1,478,662$ or $2.17 \%$ of the total population). (Thailand National Statistics Office, 2014) 5 years later, at the next survey interval, 557,397 individuals reported being in need of assistive devices (up $46.72 \%$ from previously) out of the $3,694,379$ individuals (up $149.85 \%$ from previously) surveyed with a disability, or $5.5 \%$ of the total population. (Thailand National Statistics Office, 2020) During this same 2012-2017 interval, the Wheelchair Project recorded an overall growth of $39.56 \%$ for assistive devices provided. Clearly, alternative efforts must be employed alongside the Wheelchair Project in order to adequately meet the growing needs of the disabled population.

Serious discussion must be given on strategies for the development and implementation of services for people affected by disability which allow for the provision of appropriate assistive devices without compromising the quality of care provided yet still being fiscally responsible. The diversity of needs that require an assistive device of some type necessitates a range of offerings which is broad enough to address these needs in almost all scenarios. However, through systematic analysis of these needs, it must be possible to identify devices which can appropriately meet the needs of significant portions of the population. By mass-producing devices such as these for wide disbursement, the need for technical expertise may be reduced through targeted training materials and how-to guides on these common devices' adaptation or modification. Additionally, repair and refurbishment may be simplified due to the high volume in circulation. This will also allow provisioners with specialized expertise to prioritize patients with complex or a-typical needs. Such a strategy would require a widespread data collection, a well-trained network of provisioners, and vigilant efforts to monitor and re-evaluate all aspects of this process to maintain best-practice and identify available optimizations. Government sponsorship and regulation would be critical to the success of a program of this nature and size.

The model outlined in this case study has demonstrated a viability over the Wheelchair Project's 20-year history, but development requires constant and critical re-evaluation of all strategies in order to make adjustments which adapt and along with the ever-evolving circumstances surrounding the work being done. Questioning any model is key in keeping pace with the needs and optimally leveraging available resources. E.g. At what point will local equipment production be economical and reliable enough to outpace import of foreign-made $2^{\text {nd }}$-hand wheelchairs? What role will future legislation/government insurance or welfare programs play in these efforts? What limitations will logistics and supply have when multiples of centers are established - not to even consider what facilities and support systems will be necessary to keep pace with supplying these centers? There will never be a single "correct" answer regarding an issue as acutely felt as this subject is, 
but the complexity of a problem should never deter our efforts to improve the world around us.

\section{Conclusion}

The history and proliferation of the Wheelchair Project have demonstrated a desire for the services it offers in Thailand and Southeast Asia. However, there is still more to be explored regarding this model's place as part of an overarching strategy aimed at meeting the deficit of assistive devices easily accessible to the public. This case study shows that, given the right environment and implementation, programs of this nature can be fiscally viable and sustainable. Additionally, this model demonstrates strong scalability and replication potential given its emphasis of the utilization of readily available resources and expertise, as well as the use of pre-existing training modules developed by the World Health Organization available in Thai and certified under the International Society of Wheelchair Professionals.

Independently, the Wheelchair Project is, and will continue to be, incapable of meeting its goal of providing every individual with attainable access to assistive devices. A united and coordinated effort dedicated is instrumental in achieving this goal. And while more highly developed models may provide better services to patients, the medical, logistical, manufacturing, and financial requirements needed for implementation would likely proves extremely challenging. The model showcased in this case study featuring the Wheelchair Project provides a viable "next-steps" approach for Thailand and similar regions to effectively address the needs felt by its citizens affected by disability.

\section{Acknowledge}

The Wheelchair Project would like to take this opportunity to acknowledge the many, many people, organizations, and stakeholders that make this work possible, beginning with our deep appreciation for Her Royal Highness Princess Mahachakri Sirindhorn, sponsor and royal patron of the Wheelchair Project, and without whom none of this would be possible. The Wheelchair Project would also like to express its appreciation to the Rajanagarindra Institute of Child Development and the RICD Foundation, as well as their many staff who oversee the ongoing effort of the Wheelchair Project and under whose name we serve. Furthermore, the Wheelchair Project would like to thank the many equipment donors from around the world who provide the equipment which is provided to the people of Thailand at no cost. Additionally, we would like to thank the many organizations who contribute their services, finances, and gifts-in-kind which sustain the Wheelchair Project allowing us to import equipment from abroad, transport equipment throughout the country and region for distribution, purchase tools and equipment and supplies needed in the necessary refurbishment and adaptation of equipment before it can be given to a patient, and the many other contributions too numerous to name which allow the Wheelchair Project to continue its efforts. And finally, the Wheelchair Project is indebted to the many workers, staff, and volunteers who offer their time and energy to carry on this amazing work. It is difficult to imagine a better example of the awesome power of cooperation and what we can accomplish when we work together.

\section{References}

1. Barks, L. (2004). Therapeutic Positioning, Wheelchair Seating, and Pulmonary Function of Children with Cerebral Palsy: A Research Synthesis. Rehabilitation Nursing, 29(5), 146-153.

2. Bickenbach, J. (2011). The World Report on Disability. Disability \& Society, 26(5), 655-658.

3. Bray, N., Noyes, J., Edwards, R. T., \& Harris, N. (2014). Wheelchair interventions, services and provision for disabled children: a mixed-method systematic review and conceptual framework. BMC Health Services Research, 14(1).

4. Glumac, L. K., Pennington, S. L., Sweeney, J. K., \& Leavitt, R. L. (2009). Guatemalan Caregivers' Perceptions of Receiving and Using Wheelchairs Donated for Their Children. Pediatric Physical Therapy, 21(2), 167-175.

5. Harris, A., Pinnington, L. L., \& Ward, C. D. (2005). Evaluating the Impact of Mobility-Related Assistive Technology on the Lives of Disabled People: A Review of Outcome Measures. British Journal of Occupational Therapy, 68(12), 553-558.

6. Khasnabis, C., \& Mines, K. (2013). Wheelchair service training package: Intermediate level. Geneva: World Health Organization (WHO).

7. Ploeg, H. P. V. D., Beek, A. J. V. D., Luc H V Van Der Woude, \& Mechelen, W. V. (2004). Physical Activity for People with a Disability. Sports Medicine, 34(10), 639-649.

8. Rochat, P. (1992). Self-Sitting and Reaching in 5- to 8-MonthOld Infants: The Impact of Posture and Its Development on Early Eye-Hand Coordination. Journal of Motor Behavior, 24(2), 210220.

9. Rousseau-Harrison, K., \& Rochette, A. (2012). Impacts of wheelchair acquisition on children from a person-occupationenvironment interactional perspective. Disability and Rehabilitation: Assistive Technology, 8(1), 1-10.

10. Shore, S. (2017). The long-term impact of wheelchair delivery on the lives of people with disabilities in three countries of the world. African Journal of Disability, 6.

11. Sumner, E., Oconnell, C., \& Macalpine, B. (2017). Wheelchair donation in a low-resources setting: Utilization, challenges and benefits of wheelchairs provided through a specialized seating programme in Haiti. Journal of Rehabilitation Medicine, 49(2), 178-184. doi: 10.2340/16501977-2186

12. Thailand National Statistics Office. (2020). The 2017 Disability Survey. Bangkok: Statistical Forecasting Division.

13. Thailand National Statistical Office. (2014). The 2012 Disability Survey. Bangkok: Statistical Forecasting Division.

14. Toro, M. L., Eke, C., \& Pearlman, J. (2015). The impact of the World Health Organization 8-steps in wheelchair service provision in wheelchair users in a less resourced setting: a cohort study in Indonesia. BMC Health Services Research, 16(1). 


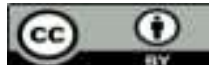

This work is licensed under Creative Commons Attribution 4.0 License

\section{To Submit Your Article Click Here: Submit Manuscript}

DOI:10.31579/2692-9392/096
Ready to submit your research? Choose Auctores and benefit from:

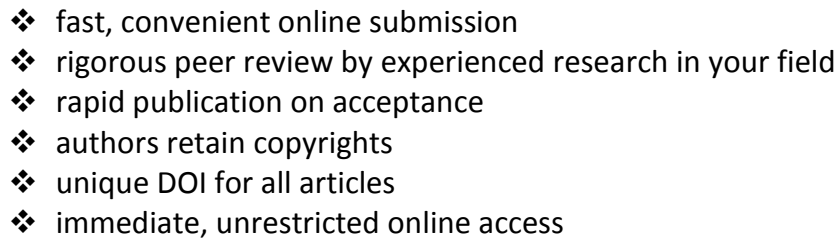

At Auctores, research is always in progress.

Learn more www.auctoresonline.org/journals/archives-of-medical-casereports-and-case-study 